\title{
Birth weight, weight at one year, and left ventricular mass in adult life
}

\author{
M Vijayakumar, C H D Fall, C Osmond, D J P Barker
}

\begin{abstract}
Objective-To examine how fetal and infant growth are related to left ventricular mass in adult life.

Design-A follow up study of men born during 1920-30 whose birth weights and weights at 1 year were recorded.

Setting-Hertfordshire, England.

Subjects -290 men born and still living in East Hertfordshire, England.

Main outcome measure-Left ventricular mass calculated from measurements of interventricular septal thickness and left ventricular posterior wall thickness and left ventricular internal diameter at end diastole measured by $M$ mode echocardiography.

Results-Left ventricular mass was highest in men with the lowest weight at 1 year and fell with increasing weight at 1 year $(r=0 \cdot 18, P=0 \cdot 01)$. Left ventricular mass was not related to birth weight. The relation with weight at 1 year was independent of factors in adult life known to influence left ventricular mass, including body size, systolic blood pressure, and age. The enlarged left ventricular mass associated with reduced growth in infancy was concentric, affecting both the interventricular septum and the left ventricular posterior wall. Concentric left ventricular hypertrophy is known to be associated with increased death rates from coronary artery disease.
\end{abstract}

Conclusion-Low weight at 1 year is associated with concentric enlargement of the left ventricle in adult life. This is consistent with a previous finding of higher mortality from cardiovascular disease in men of low weight at 1 year, and provides further evidence that cardiovascular disease may be partly programmed in early life. The left ventricular enlargement may be a long term result of haemodynamic changes in utero or of persisting changes in growth factor concentrations.

(Br Heart f 1995;73:363-367)

Keywords: birth weight; left ventricular enlargement; weight at one year; cardiovascular disease

Recent findings suggest that the pathogenesis of coronary heart disease begins in fetal life and infancy. ${ }^{1}$ Among 10141 men born during 1911-30 in Hertfordshire, England, whose birth weights and weights at 1 year were recorded, men with the lowest birth weights and weights at 1 year had the highest death rates from coronary heart disease. ${ }^{2}$ Reduced growth in utero and during infancy was also associated with an increased risk of hypertension, non-insulin dependent diabetes, ${ }^{4}$ and raised LDL cholesterol ${ }^{56}$ and fibrinogen ${ }^{7}$ concentrations in adult life. These findings have led to the hypothesis that coronary heart disease originates from early programming whereby undernutrition during sensitive periods in early development permanently changes the body's structure and physiology. ${ }^{89}$

Left ventricular hypertrophy, determined by either electrocardiography or echocardiography, has been shown to be a strong predictor of morbidity and death from coronary heart disease. ${ }^{10}$ Much of the variance in left ventricular mass in adults is unexplained by known influences, such as body size and systolic blood pressure. ${ }^{112}$ The human heart has its highest growth rates in fetal and early postnatal life. ${ }^{13}{ }^{14}$ Neither the relation between this early growth and adult left ventricular mass nor the long-term effects of early growth retardation have yet been studied. Doppler ultrasound studies have shown that in some growth retarded fetuses haemodynamic changes result in the redistribution of blood flow to the brain at the expense of the viscera and lower limbs. This redistribution is associated with an increase in left ventricular blood flow and increased peripheral arterial resistance. ${ }^{1516}$ Such haemodynamic changes could produce long-term changes in left ventricular size.

We measured left ventricular mass in a sample of men whose birth weights and weights at one year had been recorded.

\section{Patients and methods}

In Hertfordshire from 1911 onwards each birth was notified by the attending midwife, and a health visitor saw the child periodically throughout infancy. The child's birth weight and weight at one year were recorded. ${ }^{2}$ We used these records to trace men who were born in the county between 1911 and 1930, and to determine cardiovascular mortality rates. ${ }^{2}$ We subsequently examined a subsample of the men who were born in East Hertfordshire between 1920 and 1930, and still live there. Their occupation and their father's occupation at the time of their birth were used to determine social class, currently and at birth. ${ }^{17}$ Their blood pressure, ${ }^{4}$ serum lipids, ${ }^{5}$ plasma clotting factors, ${ }^{7}$ and glucose 
and insulin concentrations ${ }^{4}$ were measured, and the results have previously been reported. We reapproached the 370 men who had complete measurements on all blood samples and asked them to take part in this study. Seven of the 370 had died and 11 had moved away: $290(82 \%)$ of the remaining 352 took part. The men were visited at home by a nurse who asked for details of current smoking habits and alcohol consumption. Alcohol consumption was converted to the total number of units per week ( 1 unit $=10 \mathrm{ml}$ ethanol).

After the interview subjects were asked to come to a local clinic where left ventricular mass was measured echocardiographically according to the recommendations of the American Society of Echocardiography. ${ }^{18}$ Cross sectionally directed $M$ mode echocardiographic examination was carried out by one of two doctors (MV and CHDF), with the subjects in the partial left decubitus position, using a $2 \cdot 25 \mathrm{~Hz}$ transducer $(\operatorname{sim} 5000$, Esota Biomedica, Italy). The interventricular septum and left ventricular posterior wall, at or just below the mitral valve leaflets, were simultaneously visualised throughout the cardiac cycle. The $M$ mode cursor was placed perpendicularly to the long axis of the left ventricle. $M$ mode prints were made using a video printer (Sony UP930, Japan). Measurements of the left ventricular internal diameter at end diastole (LVIDD) and end systole (LVIDS), interventricular septal thickness at end diastole (IVSD), and left ventricular posterior wall thickness at end diastole (LVPWD) were made from the prints using a digitiser (Genius GT1212B, Taiwan). Measurements were made in five cardiac cycles and the mean was used in the analysis.

Left ventricular mass was calculated by an anatomically validated method ${ }^{19}$ using the formula: $\mathrm{LV}$ mass $=0.8 \quad[1.04$ ((IVSD + LVIDD + LVPWD $^{3}-$ LVIDS $\left.\left.^{3}\right)\right]+0.6 \mathrm{~g}$. Relative wall thickness (RWT) was calculated using the formula: [ $2 \times($ LVPWD/LVIDD)]. Left ventricular volume was calculated using Teichholz formulae, ${ }^{19}$ and the ratio between left ventricular mass and left ventricular volume at end diastole ( $\mathrm{M} / \mathrm{V}$ ratio) was derived. The RWT and $M / V$ ratio are indicators of the concentricity of left ventricular hypertrophy. ${ }^{19}$ Cardiac output (CO) was calculated as (stroke volume $\times$ heart rate).

The men's weight was measured on a Seca scale and their height was measured on a portable stadiometer (CMS Instruments Ltd). Body surface area $\left(\mathrm{m}^{2}\right)$ was calculated using the formula: $0.007184 \times\left(\right.$ weight $\left.(\mathrm{kg})^{0.425}\right) \times$ (height $\left.(\mathrm{cm})^{0.725}\right){ }^{20}$ Systolic and diastolic blood pressures were measured with an automated device (Dinamap, Critikon, Ascot) and a cuff of the appropriate size. The Rose/WHO chest pain questionnaire was administered. ${ }^{21}$ A 12 lead electrocardiograph was obtained according to the 1982 Minnesota protocol. ${ }^{22}$ Electrocardiographs were coded by two trained coders who were blind to the infant data. Men were defined as having coronary heart disease if one or more of the following were present: a history of typical angina according to the Rose/WHO chest pain questionnaire, ECG Minnesota codes 1-1 or 1-2 (major $Q$ waves), or a history of coronary artery revascularisation surgery.

\section{STATISTICAL METHODS}

The distributions of left ventricular mass and $\mathrm{M} / \mathrm{V}$ ratio were skewed. We transformed the values using logarithms. Differences in left ventricular mass in men with and without coronary heart disease were assessed by a two sample $t$ test, and differences between smokers, non-smokers, and ex-smokers were assessed by one way analysis of variance. Multiple linear regression analysis was used to analyse the relation of left ventricular mass with birth weight, weight at one year, factors in adult life known to influence ventricular mass including body size, age, and systolic blood pressure and other potential confounding factors including social class (treated as an ordinal variable) and alcohol consumption.

\section{Results}

Of the 290 men examined we excluded five with valvar heart disease and two with left ventricular dyskinesia. In a further $81(29 \%)$ men suitable views of the left ventricle were not obtained: in 32 this was because an inadequate parasternal echogenic window made it impossible to align the $M$ mode cursor perpendicularly to the long axis of the left ventricle and in 49 either the posterior septal wall or the posterior ventricular wall was not seen distinctly enough to make measurements. The analysis is based on 202 men. Their mean age was 66.9 (SD 3.2) years.

Their geometric mean left ventricular mass was $203 \mathrm{~g}$ (range 103-377 g; geometric standard deviation $1 \cdot 26$ ). Left ventricular mass was higher in men of larger body size, rising with increasing body mass index (weight $(\mathrm{kg}) /$ height $\left.(\mathrm{m})^{2}\right)(r=0.25 ; \mathrm{P}=0.0003)$, and with increasing body surface area $(r=0.21$; $P=0.002)$. It also rose with increasing systolic blood pressure $(r=0.27 ; \mathrm{P}=0.0001)$ and with increasing age $(r=0.13 ; \mathrm{P}=0.07)$. Geometric mean left ventricular mass was higher $(226 \mathrm{~g})$ in the 33 men with coronary heart disease than in the men without $(199 \mathrm{~g})$ (difference $27 \mathrm{~g} ; 95 \%$ C.I. 8 to $47 ; \mathrm{P}=$ $0.004)$. There were no significant differences in left ventricular mass between smokers (geometric mean $203 \mathrm{~g}, \mathrm{n}=30$ ), ex-smokers (geometric mean $205 \mathrm{~g}, \mathrm{n}=136$ ), and lifetime non-smokers (geometric mean $198 \mathrm{~g}$, $\mathrm{n}=36$ ). Left ventricular mass was not related to alcohol consumption, current social class, or social class at birth.

Table 1 shows mean left ventricular mass according to the men's weight at one year (see also figure) and birth weight. Values in table 1 are shown both unadjusted and adjusted for surface area, the measure of body size against which left ventricular mass is traditionally indexed. Left ventricular mass was highest among men in the lowest group of weight at one year, and fell progressively with increasing weight at one year $(r=0 \cdot 18, P=0 \cdot 01))$. Left 
Table 1 Geometric mean left ventricular mass according to weight at age one year and birth weight

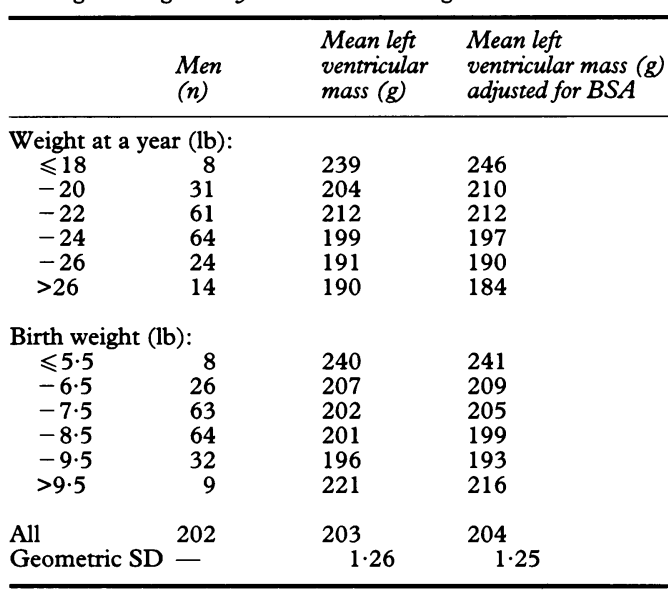

One pound $=0.454 \mathrm{~kg}$.

Table 2 Geometric mean left ventricular mass according to current body surface area and weight at one year of age

\begin{tabular}{lllll}
\hline $\begin{array}{l}\text { Weight } \\
\text { at one } \\
\text { year }(l b)\end{array}$ & \multicolumn{4}{l}{ Mean body surface area } \\
\cline { 2 - 5 } & $\leqslant 1.87 m^{2}$ & $-1.98 m^{2}$ & $>1 \cdot 98 m^{2}$ & All \\
\hline$\leqslant 21$ & $198(25)$ & $227(22)$ & $236(9)$ & $215(56)$ \\
-23 & $199(25)$ & $201(20)$ & $222(26)$ & $208(71)$ \\
$>23$ & $172(16)$ & $181(27)$ & $211(32)$ & $191(75)$ \\
All & $192(66)$ & $201(69)$ & $218(67)$ & $203(202)$ \\
\hline
\end{tabular}

Figures in parentheses are numbers of men.

Table 3 Multiple regression analysis of log left ventricular mass (g) with body surface area, systolic blood pressure, age, and weight at one year

\begin{tabular}{|c|c|c|c|}
\hline Variable & $\begin{array}{l}\text { Regression } \\
\text { coefficient }\end{array}$ & $S E$ & $P$ value \\
\hline $\begin{array}{l}\text { Body surface area } \\
\left(\mathrm{m}^{2}\right)\end{array}$ & 0.4510 & $0 \cdot 1170$ & 0.0002 \\
\hline $\begin{array}{l}\text { Systolic blood pressure } \\
(\mathrm{mm} \mathrm{Hg})\end{array}$ & 0.0027 & 0.0008 & 0.001 \\
\hline Age (y) & 0.0047 & 0.0048 & 0.3 \\
\hline $\begin{array}{l}\text { Weight at one year } \\
\text { (lb) }\end{array}$ & -0.2005 & 0.0004 & 0.002 \\
\hline Constant & $4 \cdot 2094$ & & \\
\hline
\end{tabular}

$\mathrm{y}$ variable $=\log$ left ventricular mass $(\mathrm{g})$. ventricular mass also fell with increasing birth weight, although the trend was not statistically significant $(r=0.08, P=0.3)$. The significance of the trend with weight at one year was increased $(P=0.0004)$ in a simultaneous analysis with current body surface area. The highest mean LV mass was in men who had been light at one year and were currently large (table 2). Multiple regression analysis (table 3) showed that the relation of LV mass to weight at one year was independent of current surface area, systolic blood pressure, and age.

Table 4 shows the echocardiographic measurements of the left ventricle as well as the calculated values of relative wall thickness, $\mathrm{M} / \mathrm{V}$ ratio, and cardiac output according to weight at one year. Interventricular septal thickness and left ventricular posterior wall thickness at end diastole, relative wall thickness, and $M / V$ ratio were inversely related to weight at one year. Thus the increase in left ventricular size associated with low weight at one year is concentric. Left ventricular internal diameter and calculated cardiac output were not related to weight at one year. None of the variables measured was related to birth weight.

The relation of left ventricular mass to other biochemical and haematological risk factors for cardiovascular disease, including plasma fibrinogen and factor VII concentrations; serum LDL cholesterol, HDL cholesterol, and triglyceride concentrations; and plasma glucose and insulin concentrations (fasting and after an oral glucose load) was examined. Plasma fibrinogen and serum LDL cholesterol concentrations were both positively related to left ventricular mass $(r=0 \cdot 19$, $\mathrm{P}=0.006$ and $r=0.17, \mathrm{P}=0.02$ respectively), independently of body mass index. None of the other risk factors was related to left ventricular mass. We have previously shown that plasma fibrinogen concentrations were higher in men who had low weight at one year. ${ }^{7}$ Left ventricular mass remained significantly inversely related to weight at one year $(P=0.02)$, after allowing for plasma

Table 4 Echocardiographic measurements of the left ventricle and calculated values of relative wall thickness, $M / V$ ratio and cardiac output according to weight at one year

\begin{tabular}{|c|c|c|c|c|c|c|c|c|c|c|}
\hline \multirow[b]{2}{*}{ Variable } & \multicolumn{6}{|c|}{ Weight at one year (pounds) } & \multirow[b]{2}{*}{ All } & \multirow[b]{2}{*}{$S D$} & \multirow{2}{*}{$\begin{array}{l}P \text { valuet } \\
\text { for trend }\end{array}$} & \multirow{2}{*}{$\begin{array}{l}P \text { value }{ }^{\star} \text { for } \\
\text { trend allowing } \\
\text { for current } \\
B S A\end{array}$} \\
\hline & $\leqslant 18$ & $18-20$ & $20-22$ & $22-24$ & $24-26$ & $>26$ & & & & \\
\hline \multicolumn{11}{|l|}{ Measured values: } \\
\hline $\begin{array}{l}\text { Left ventricular internal } \\
\text { diameter at end diastole } \\
\text { (LVIDD) (mm) }\end{array}$ & $46 \cdot 1$ & $45 \cdot 3$ & $45 \cdot 7$ & $46 \cdot 3$ & $45 \cdot 6$ & $47 \cdot 4$ & $46 \cdot 0$ & $5 \cdot 1$ & $0 \cdot 4$ & $0 \cdot 9$ \\
\hline $\begin{array}{l}\text { Left ventricular internal } \\
\text { diameter at end systole } \\
\text { (LVIDS) (mm) }\end{array}$ & $24 \cdot 2$ & $23 \cdot 9$ & $24 \cdot 8$ & $25 \cdot 3$ & $23 \cdot 9$ & $25 \cdot 1$ & $24 \cdot 7$ & $4 \cdot 3$ & $0 \cdot 6$ & $1 \cdot 0$ \\
\hline $\begin{array}{l}\text { Interventricular septal } \\
\text { thickness at end diastole } \\
\text { (IVSD) (mm) }\end{array}$ & $15 \cdot 1$ & $14 \cdot 2$ & $14 \cdot 3$ & $13 \cdot 6$ & $13 \cdot 5$ & $12 \cdot 8$ & $13 \cdot 9$ & $2 \cdot 5$ & 0.009 & 0.003 \\
\hline $\begin{array}{l}\text { Left ventricular posterior wall } \\
\text { thickness at end diastole } \\
\text { (LVPWD) (mm) }\end{array}$ & $11 \cdot 9$ & $10 \cdot 5$ & $10 \cdot 8$ & $10 \cdot 1$ & $9 \cdot 9$ & $9 \cdot 7$ & $10 \cdot 4$ & $1 \cdot 8$ & 0.001 & 0.0005 \\
\hline \multicolumn{11}{|l|}{ Calculated values: } \\
\hline Relative wall thickness (RWT) & 0.53 & $0 \cdot 47$ & 0.48 & 0.44 & 0.44 & 0.42 & 0.46 & $0 \cdot 1$ & 0.004 & 0.007 \\
\hline $\mathrm{M} / \mathrm{V}$ ratio $(\mathrm{g} / \mathrm{ml})$ & $2 \cdot 5$ & $2 \cdot 2$ & $2 \cdot 2$ & $2 \cdot 0$ & $2 \cdot 0$ & 1.9 & $2 \cdot 1$ & $1 \cdot 3^{\star}$ & 0.002 & 0.002 \\
\hline Cardiac output $(\mathrm{CO})(1 / \mathrm{min})$ & $4 \cdot 3$ & $4 \cdot 6$ & $4 \cdot 8$ & $4 \cdot 9$ & $4 \cdot 7$ & $5 \cdot 0$ & $4 \cdot 8$ & $1 \cdot 3$ & $0 \cdot 2$ & 0.6 \\
\hline Numbers of men & 8 & 31 & 61 & 64 & 24 & 14 & 202 & & & \\
\hline
\end{tabular}

${ }^{\star}$ Geometric standard deviation. †Multiple linear regression. 


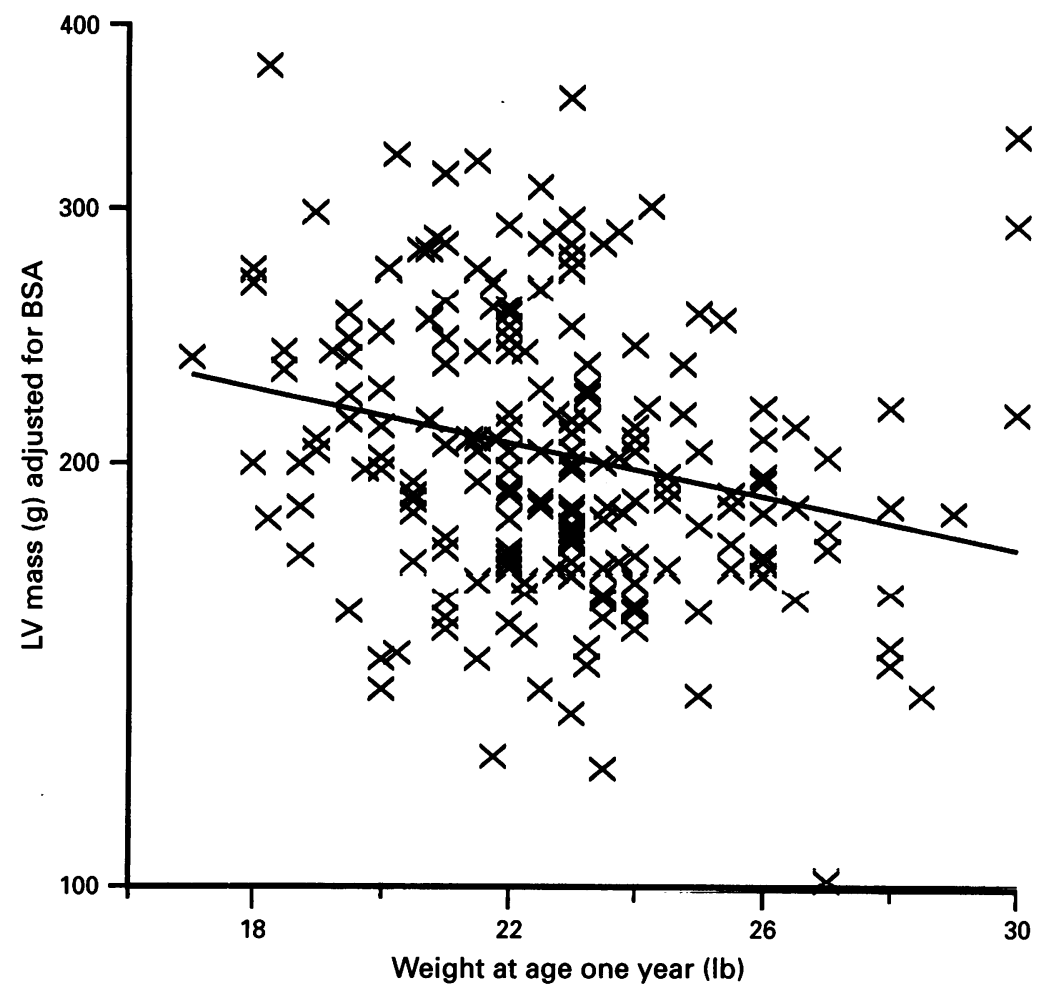

Adult left ventricular mass according to weight at one year. rate was similar to other studies in this age group. ${ }^{23}$ There were no differences in age, body mass index, body surface area, systolic blood pressure, birth weight or weight at one year between men for whom we did or did not measure left ventricular mass.

Although growth during infancy may be influenced by feeding, the relation of coronary heart disease mortality to weight at one year is independent of method of feeding in infancy. ${ }^{3}$ Undernutrition in late pregnancy may be followed by growth failure in infancy. At birth the baby may be short but have a normal birth weight. ${ }^{9}$ Raised plasma fibrinogen concentrations in adult life are associated with shortness at birth, and low weight at one year, but not with low birth weight. ${ }^{7}$ A common origin in undernutrition in late gestation could explain the association between left ventricular mass and raised plasma fibrinogen in our study. A similar explanation could account for the association between left ventricular mass and LDL cholesterol.

One link between undernutrition in late gestation and persisting increase in left ventricular mass could be mediated through cardiovascular adaptive changes in utero. ${ }^{24}$ In late gestation the human fetus may respond to nutrient deprivation by maintaining the brain growth at the expense of the growth of the trunk. The redistribution of blood flow that accompanies this is associated with an increase in peripheral resistance, a reduction in blood flow in the abdominal aorta, and an increase in left ventricular blood flow. ${ }^{15} 16$ These changes may lead to permanent left ventricular enlargement.

Another possible link between undernutrition in late gestation and left ventricular mass is persisting changes in hormones which regulate growth. We have previously suggested that failure of infant growth is associated with defects in the growth hormone/ insulin-like growth factor axis. ${ }^{9}$ These may influence cardiovascular structure. Both growth hormone and insulin-like growth factor-1 stimulate ventricular growth, effects which are evident in acromegaly.

We thank the men who took part in the study, the staff of National Health Service Central Registry, Southport, and Hertfordshire Family Health Services Authority who helped to trace the men. The fieldwork was coordinated by Mrs P Harwood. Nurses S Haynes, P Howell, R Rosenthal, and S Wolfe carried out the home interviews and helped with the clinics. ECGs were coded by Mrs C Rose and Mrs N Keen. M V was a Commonwealth Research Fellow. The study was funded by the Medical Research Council. not related to birth weight. We have ously shown that in men weight at one year is a stronger predictor of mortality from coronary heart disease than is birth weight. ${ }^{3}$

Our study was confined to men born and still living in East Hertfordshire, and willing to take part. This introduced the possibility of selection bias. However, our analysis was based on comparisons within the sample, and bias would be introduced only if the relation between early growth and coronary heart disease were different in those studied and not studied. This seems unlikely. It was not possible to obtain adequate echocardiographic views for measurement of left ventricular mass in $29 \%$ of the men. This is a recognised problem, especially in the elderly, and our success

1 Barker DJP. Fetal origins of coronary heart disease. $B$ Heart F 1993;69:195-6.

2 Barker DJP, Winter PD, Osmond C, Margetts B, Simmonds SJ. Weight in infancy and death from ischaemic heart disease. Lancet 1989;ii:577-80.

3 Osmond C, Barker DJP, Winter PD, Fall CHD, Simmonds SJ. Early growth and death from cardiovascular disease in women. BMF 1993;307:1519-24.

4 Hales CN, Barker DJP, Clark PMS, Cox LJ, Fall CHD, Osmond C. Fetal and infant growth and impaired glucose tolerance at age 64. BMF 1991;303:1019-22.

5 Fall CHD, Barker DJP, Osmond C, Winter PD, Clark PMS, Hales CN. Relation of infant feeding to adult PMS, Hales CN. Relation of infant feeding to adult ischaemic heart disease. BMf 1992;304:801-5. 
6 Barker DJP, Martyn CN, Osmond C, Hales CN, Fall $\mathrm{CHD}$. Growth in utero and serum cholesterol concen CHD. Growth in utero and serum cholester
trations in adult life. $B M \Im$ 1993;307:1524-7.

7 Barker DJP, Meade TW, Fall CHD, Phipps K, et al. Relation of fetal and infant growth to plasma fibrinogen and factor VII concentrations in adult life. $B M \mp 1992 ; 304: 148-52$.

8 Lucas A. Programming by early nutrition in man. In: Bock GR, Whelan J, eds. The Childhood Environment and Adut Disease; Ciba Foundation Symposium 156. Chichester, England: John Wiley, 1991:38-55.

9 Barker DJP, Gluckman PD, Godfrey KM, Harding JE, Owens JA, Robinson JS. Fetal nutrition and cardiovascular disease in adult life. Lancet 1993;341:938-41.

10 Levy D, Garrison RJ, Savage DD, Kannel WB, Castelli WP. Prognostic implications of Echocardiographically determined left ventricular mass: the Framingham Study. N Engl ₹ Med 1990;322:1561-6.

11 Frohlich ED, Tarazi RC. Is arterial pressure the sole factor responsible for hypertensive cardiac hypertrophy? $A m \mathcal{F}$

12 Devereux RB, Lutas EM, Casale PN, Kligfield P, Eisenberg RR, Hansmond IW, et al. Standardisation of M-mode echocardiographic left ventricular anatomic measurements. $\mathscr{f} A C C$ 1984;4:1222-30.

13 Rakusan K. Cardiac growth, maturation and ageing. In Zak R, ed. Growth of the heart in health and disease. New York: Raven Press, 1984;131-64.

14 Ishii A, Tatsunami S, Satah I, Honma T, Hamada $H_{\text {, }}$ Yago N, et al. Growth dynamics of the heart from perinatal period to childhood. F Perinat Med 1990;18: 459-63.

15 Al-Ghazali W, Chita SK, Chapman MG, Allan LD. Evidence of redistribution of cardiac output in asymmet- rical growth retardation. $B r \mathcal{f}$ Obstet Gynecol 1989;96: 697-704.

16 Rizzo G, Arduini D. Fetal cardiac function in intrauterine growth retardation. Am $\mathcal{f}$ Obstet Gynecol 1991;165:

17 Office of Population Censuses and Surveys. Classification of occupations 1980. London: HMSO, 1980.

18 Sahn DJ, De Maria A, Kisslo J, Weyman A. The committee on M-mode standardisation of the American Society of Echocardiography, Recommendations regarding quantitation in M-mode Echocardiography. Results of a survey of Echocardiographic Measurements. Circulation 1978; 58:1072-83.

19 Devereux RB, Alonso DR, Lutas EM, Gottlieb GJ, Campo E, Sachs I, Reichek N. Echocardiographic assessment of left ventricular hypertrophy: Comparison to necropsy findings. Am $\mathcal{f}$ Cardiol 1986;57:450-8.

20 DuBois D, DuBois EF. A formula to estimate the approximate surface area if height and weight be known. Arch mate surface area if height

21 Rose GA Blackburn H. Cardiovascular survey methods. World Health Organisation Monograph Series No. 56.

22 Prineas RJ, Crow RS, Blackburn H. The Minnesota Code Manual Of Electrocardiographic Findings: Standards and Procedures for Measurement and Classification. Boston: John Wright, 1982.

23 Levy D, Garrison RJ, Savage DD, Kannel WB, Castelli WP. Left ventricular mass and incidence of coronary heart disease in an elderly cohort. Ann Int Med 1989; 110:101-7.

24 Dicke JM. Poor obstetrical outcome. In: Pauerstein CJ, ed. Clinical obstetrics. Edinburgh: Churchill Livingstone, 1987:421-39. 